\title{
UMA DISCUSSÃO SOBRE UMA EPISTEMOLOGIA NA EDUCOMUNICAÇÃO E SUA UTILIZAÇÃO NO COTIDIANO ESCOLAR NO CURRÍCULO FORMAL E INFORMAL
}

\author{
ADISCUSSION ABOUT ANEPISTEMOLOGY IN \\ EDUCOMMUNICATION AND ITS USE IN SCHOOLDAILY \\ IN THE FORMAL AND INFORMAL CURRICULUM
}

\author{
Cláudio Joaquim dos Santos Braga \\ Universidade Federal do Rio de Janeiro (UFRJ) \\ ORCID: 0000-0002-4060-7435 \\ Data de submissão: 02/03/2019 \\ Data de aprovação:10/04/2019
}

\section{RESUMO}

As novas tecnologias de informação e comunicação transformaram métodos, atividades, a forma de comunicação entre alunos e professores e mudou o ambiente escolar. As novas tecnologias intensificaram os aspectos colaborativos do ensino/ aprendizado e toda esta dinâmica está à disposição dos professores e alunos. No entanto, é preciso um olhar reflexivo e crítico sobre o uso das novas tecnologias, pois está em jogo a comunicação, a memória, a interação, os novos comportamentos aprendidos. Tudo isto vincula-se ao conceito de educomunicação, que no cotidiano escolar permite integrar atividades pedagógicas, ampliar a possibilidade de comunicação, promoção e disseminação do conhecimento. Daí a importância de uma Teoria do Conhecimento - uma Epistemologia - que apoie a prática profissional docente no compromisso integral de ensinar, juntando tecnologia e a percepção e a vivência do bem comum.

Palavras-chave: Educomunicação. Mídias digitais. Redes sociais. Valores éticos. Currículo.

\section{ABSTRACT}

The new information and communication technologies transformed methods, activities, the form of communication between students and teachers and changed the school environment. New technologies have intensified the collaborative aspects of teaching / learning and all this dynamics is available to teachers and students. However, it takes a critical and reflexive look at the use of new technologies, because communication, memory, interaction, and new learned behaviors are at stake. All this is linked to the concept of educommunication, which in the school daily allows to integrate pedagogical activities, to increase the possibility of communication, promotion and dissemination of knowledge. Hence the importance of a Theory of Knowledge - an Epistemology that supports professional teaching practice in the integral commitment to teach, joining technology and the perception and the experience of the common good.

Keywords: Educommunication. Digital media. Social networks. Ethical values. Curriculum. 


\section{INTRODUÇÃO}

Com os constantes avanços da tecnologia evoluindo a cada dia, nossas possibilidades de comunicação e interação prosperam, via diversos aparatos tecnológicos. A educação apropriou-se de muitos desses aparatos que hoje já estão incorporados em muitos ambientes escolares (BRITO; PURIFICAÇÃO, 2008, p. 22).

O termo Educomunicação foi cunhado pela primeira vez pelo comunicadoreducador uruguaio Mario Kaplún, que oficialmente uniu a educação e os processos midiáticos de comunicação em um processo que poderia ser reproduzido e adaptado a diversas realidades em um ambiente escolar (SARTORI, 2010, p. 43).

Educomunicação une a educação e a mídia, o uso das mídias na educação, a produção de conteúdos educativos, a gestão democrática das mídias e a prática epistemológica e experimental do ambiente tecnológico (NCEUSP, 2019).

Pode-se notar que, além da sua estreita ligação com a tecnologia, o conceito também se relaciona a uma reflexão crítica sobre os pressupostos do uso das novas tecnologias de informação e comunicação nos processos educacionais, permitindo uma interação comunicativa e produção de conhecimentos, via projetos colaborativos, em que, através de ecossistemas comunicativos e participativos, oferecem oportunidade da construção do saber, construindo em paralelo a cidadania e o direito à expressão (TORRES, 2004, p. 3). Com base nesses sistemas educomunicativos, incentivamos a curiosidade epistemológica dos nossos alunos e, com as ferramentas adequadas, eles podem produzir conhecimentos e novos saberes.

A Epistemologia é o estudo crítico dos princípios, hipóteses e resultados das diversas ciências. "Trata-se, pois, de uma reflexão epistemológica cuja preocupação fundamental é a de situar os problemas tais como eles se colocam ou se omitem, se resolvem ou desaparecem na prática efetiva dos cientistas" (JAPIASSU, 1992, p. 27).

[...] Trata-se de um olhar reflexivo e crítico sobre as ciências [...] Assim, esse ramo da Filosofia busca compreender as teorias que fundamentam o conhecimento humano e ainda questiona, critica e investiga questões acerca do que já está constituído cientificamente. Desse modo, se algo já foi comprovado cientificamente, a Epistemologia coloca em discussão os pressupostos de tal método de comprovação, visando verificar a consistência ou não dos argumentos fundamentais utilizados. (BATISTA; GOUVEIA; SOUZA, 2016, p. 52)

Nossa sociedade está cada dia mais conectada ao mundo virtual, utilizando diversos recursos tecnológicos associados ao uso da Internet (KLERING, 2015). Sendo assim, o problema que trazemos neste artigo relaciona-se a três variáveis: ensino/ aprendizado; TICs1 e sistemas pedagógicos. Três variáveis que destacam uma problemática que ultrapassa os muros da escola para um ensino/aprendizado cuja finalidade é a educação do aluno.

Daí a importância de um professor que ama o que faz e que seja comprometido com sua práxis e, como já disse Freire (FREIRE, 2014), "Professor é um ser inacabado e consciente de seu inacabamento", por isso o aprendizado deve ser contínuo.

As novas tecnologias destacam a educomunicação e apresentam-se como uma realidade que pode ser utilizada de forma pedagógica em muitas unidades escolares. Por mais simples que sejam os usos, desde um Facebook, um whatsapp; um hipertexto, um blog, um site, um editor de texto ou aplicativos e jogos, as novas tecnologias digitais e mídias 
sociais estão abrindo novas fronteiras para o aprendizado colaborativo, pois ninguém está sozinho na Rede, vários nós tecnológicos e humanos sustentam a educomunicação. (PATRÍCIO; GONÇALVES, 2010, p. 593595).

Educomunicação não é só uma proposta metodológica para as escolas, mas é um ambiente digital que reúne pessoas, tecnologias e valores éticos, que se intensifica com o uso dos celulares, que podem transformar a educação em afetivo aprendizado, porque coloca as pessoas em contato com um mundo real e inteiramente a ser descoberto.

[...] levando em conta o total de alunos de escolas públicas e particulares, o acesso à Internet exclusivo pelo telefone celular foi mais frequente entre estudantes das regiões Norte (32\%) e Nordeste (29\%) do que entre aqueles das regiões Sul (10\%), Sudeste (14\%) e CentroOeste $(15 \%)$. O uso do telefone celular está presente também nas atividades de ensino e aprendizagem. (TIC ESCOLAS, 2017, p. 29).

Estamos em um cenário em que o mais importante está em ensinar como interagir com esses materiais virtuais para contribuir com a construção de um conhecimento integral, despertando o interesse e a participação dos alunos, mas ao mesmo tempo ensinando a reconhecer os desafios de seu próprio aprendizado, que passa por acessar materiais de estudo que estão disponibilizados pelos professores, em formatos da tecnologia digital, e "[...] A maioria das aprendizagens atuais resulta das interações com diversos referentes e, em especial, com as telas e seus dispositivos tecnológicos" (GÓMEZ, 2014, p. 76).

Os professores, ao ensinarem a acessar esses referentes diversos, devem ter em mente que o aluno está em formação e que sua curiosidade e criatividade devem estimulá-los a florescer como um ser humano reflexivo e refletor de valores éticos e de boas práticas no estudo e no trabalho. As novas tecnologias podem ser usadas com este sentido; elas são uma realidade e devem ser usadas em prol da formação integral do aluno.

[...] O acesso à Internet está disseminado entre os professores, especialmente no que tange ao uso de telefones celulares. Em 2017, $97 \%$ dos docentes que lecionavam em escolas localizadas em áreas urbanas afirmaram utilizar o dispositivo para acessar a rede - em 2013 , o percentual era de $38 \%$. Entre os alunos, os dados evidenciam que ainda permanecem desigualdades. Apesar de $85 \%$ dos estudantes de escolas localizadas em áreas urbanas serem considerados usuários de Internet, ou seja, acessaram a rede nos três meses anteriores à realização da pesquisa, $22 \%$ daqueles que frequentam escolas públicas realizaram esse acesso exclusivamente pelo telefone celular, percentual que foi de apenas $2 \%$ entre os alunos de escolas particulares. (TIC ESCOLAS, 2017, p. 28 - 29).

As possibilidades pedagógicas das mídias digitais diversas, associadas aos recursos tecnológicos de comunicação, colaboração e disseminação do conhecimento através de redes sociais e aplicativos para mobile, permitem que ecossistemas comunicativos abertos possam ajudar na relação ensino e aprendizado - com ênfase numa educação integral no cotidiano escolar, evitando uma "pedagogia bancária", criticada por Freire (2014). O educador precisa ser um problematizador, [...] conduzindo o aluno para desenvolver a dúvida, a curiosidade, para comparar, constatar para ir além de seus próprios condicionamentos (FREIRE, 2014). 


\section{REFERENCIAL TEÓRICO}

\subsection{Educomunicação no cotidiano escolar}

Observamos que o cotidiano escolar já não é mais o mesmo que no século $X X$ e em outros momentos da história por conta de tantos aparatos tecnológicos disponíveis, em alguns casos por parte das escolas ou mesmo pelos próprios alunos através de seus aparelhos celulares, que são, na verdade, uma união entre computador, telefone, sistema de comunicação, câmera fotográfica, filmadora, gravador de som, sistema de transmissão ao vivo, relógio, calendário e muito mais. Nossos alunos, desde muito jovens, já crescem imersos à influência da tecnologia (PATRÍCIO; GONÇALVES, 2010, p. 593-595). E eles precisam de um professor ou professora na disciplina ensinada que saiba juntar de forma inconsútil3 tecnologia e pedagogia.

Concordamos com Cysneiros (1999), citando um texto de Papert, em que demonstra como em muitos casos, apesar da tecnologia educacional avançar, muitas de nossas aulas continuam sendo aplicadas como em séculos passados. Ao demonstrar a evolução da tecnologia e o seu uso em sala de aula, Papert escreve uma anedota que se tornou comum nos meios educacionais que envolvem tecnologia e educação. Ele conta que se médicos cirurgiões e professores do século dezenove acordassem hoje, esses profissionais teriam reações bem diferentes. Os médicos não estariam familiarizados com as atuais salas de cirurgia, devido ao avanço da medicina, mas os professores conseguiriam exercer sua função em sala de aula cem anos depois.

Em grande medida, tal complexidade está na observância de que o ato de lecionar depende essencialmente de conhecimentos específicos da disciplina ensinada e de conhecimentos didático-pedagógicos. No entanto, o domínio desses conhecimentos é ainda insuficiente para que o professor possa desenvolver seu trabalho prático, em razão da imprevisibilidade dos espaços de ensino-aprendizagem, já que "[...] professorar não é uma atividade burocrática para a qual se adquire conhecimentos e habilidades técnico-mecânicas" (PIMENTA,1997, p. 6).

Há algo mais que a transmissão e aplicação de um conhecimento específico. Isso significa que, no seu contexto de atuação, o professor irá se deparar com situações para as quais o domínio se revelará pouco seguro de conceitos, fórmulas, teorias e regras para a conquista da atenção e do entusiasmo de seus alunos. Uma das queixas mais recorrentes dos discentes é quanto ao fato de que os conteúdos e abordagens, muitas vezes, mostram-se distantes de suas realidades e de seus interesses. (Re)pensar a relação entre a teoria e a prática pode não só melhorar a qualidade da educação, como também pode contribuir com a construção de uma epistemologia atual da prática profissional docente. (BATISTA; GOUVEIA; SOUZA, 2016, p. 54).

É bom lembrar, neste contexto, que as queixas dos alunos ligadas às abordagens didático-pedagógicas não serão resolvidas pela tecnologia, se o docente não mudar a sua postura no desenvolvimento e sistematização do conhecimento, visando a prática docente e a ética. Nas escolas onde grande parte dos alunos possuem celulares, é perceptível o interesse dos alunos pelos aparelhos e suas possibilidades.

Em 2015, 36\% dos professores de escolas públicas afirmavam realizar atividades educacionais com o uso do telefone celular, esse percentual subiu para $53 \%$ em 2017 . Entre os professores de escolas particulares, o percentual era de $46 \%$ em 2015 , passando para $69 \%$ em 2017. A proporção de alunos que afirmaram utilizar o dispositivo 
para realizar atividades para a escola a pedido dos professores confirma a sua relevância no processo de aprendizagem: 53\% entre os alunos de escolas públicas e $60 \%$ entre os de escolas particulares. (TIC ESCOLAS, 2017, p. 29).

É importante observar que uma ferramenta tecnológica por si só não corresponde a um recurso pedagógico, que só passa a ser importante quando dentro de um projeto educacional; essa tecnologia é inserida e utilizada com os conteúdos de interesses da escola, sendo esses do currículo formal ou informal. A tecnologia, sem ter um projeto pedagógico embasado não representa um avanço na relação de ensino e aprendizagem do aluno.

Para o bem ou para o mal, o ensino como atividade tradicional está sendo desafiado fortemente, sem que isso signifique que esteja desaparecendo ou vá extinguir-se. Simplesmente terá de se reacomodar, encontrar outros modos e estratégias para continuar sendo importante na educação, em um contexto diferente, revolucionado em grande medida pela presença e alcances das novas tecnologias de informação. (GÓMEZ, 2014, p. 77).

Neste contexto nota-se que os alunos dominam as tecnologias, mas não sabem conviver com o próximo, desconhecem suas próprias necessidades, não sabem resolver problemas éticos, mas resolvem rapidamente problemas de lógica matemática.

A tecnologia disponível precisa ser usada para despertar diversos canais sensoriais, e a mídia utilizada - seja o quadro, com aulas repletas de oratórias e exemplos verbais, um Datashow ou TICs - não pode reproduzir apenas o que seria escrito no quadro da sala de aula, mas levar o aluno a abstrair conceitos e valores, a partir do que lhe é ensinado pelo professor. Este uso atual e intensificado das novas tecnologias tem que ser usado em prol de uma educação de qualidade.

O acesso à Internet nos domicílios voltou a crescer em 2017, enquanto o acesso móvel continuou sendo mais utilizado do que o fixo por domicílios de baixa renda e da região Norte. Contudo, ainda persistem desigualdades marcantes segundo classe socioeconômica e entre áreas urbanas e rurais. Além disso, 19\% dos domicílios conectados não possuíam computador, o que representava 13,4 milhões de residências. Essa proporção era de apenas 4\% em 2014. A proporção de usuários de Internet no Brasil alcançou 120,7 milhões de brasileiros. As atividades mais mencionadas durante o uso da Internet continuam sendo o envio de mensagens e o uso de redes sociais, porém o acesso a conteúdos audiovisuais tem apresentado crescimento nos últimos anos. (TIC DOMICÍLIO, 2018, p. 24).

Nesse cenário atual, em que a realidade permite a inclusão de diversas mídias de comunicação no cotidiano escolar, a educomunicação amplia a possibilidade na distribuição do saber, integrando valores, alunos, professores e comunidade, tanto na utilização do currículo formal como informal.

Segundo Paulo Freire (2009), o professor deve ter competência científica, generosidade, autoridade democrática, ética, comprometimento e saber escutar. E mais, deve reconhecer que ensinar exige compreender que a educação é uma forma de intervenção no mundo.

Observa-se o avanço cada vez mais rápido da utilização de novas tecnologias, redes sociais e mídias digitais no cotidiano. Estamos envolvidos em um desafio constante de integrar nosso dia a dia a todas essas informações e mídias digitais, tendo o professor um desafio ainda maior em estar sempre em uma formação 
continuada para acompanhar esses avanços tecnológicos que, com poucos anos de diferença, já deixa alguns hardwares ou softwares desatualizados ou desinteressantes. São grandes os desafios, pois não se pode desvincular a escola das possibilidades reais da família e é neste espaço sensível que o professor atua.

Uma das barreiras para o aumento da demanda é a distribuição da renda familiar. Como metade da população pesquisada apresenta renda familiar de até dois salários mínimos ( $R \$ 1.576,00)$, a contratação e uso de Internet banda larga, aos preços ofertados, ainda aparecem como itens caros para famílias com muitos membros. De modo geral, as variáveis utilizadas foram significativas. Os domicílios da área urbana, das classes A e B, com renda familiar acima de cinco salários e cujo chefe tenha escolaridade alta têm maior probabilidade de contratar o serviço de Internet banda larga do que aqueles da área rural, das classes $\mathrm{C}, \mathrm{D}$ ou $\mathrm{E}$, com renda familiar abaixo de cinco salários mínimos e cujo chefe tenha baixa escolaridade (TIC DOMICÍLIO, 2018, p. 64).

O mundo está muito dinâmico; é possível o aluno, no horário do recreio, transmitir ao vivo um jogo em sua quadra de esporte, enquanto outro participa de um debate com amigos de uma escola em outra parte do mundo (FEDOCE, 2011, p. 14-19).

Muitas escolas dedicam esforços para se atualizarem, tanto na formação continuada dos profissionais como no uso adequado de tecnologias, porém muitas ainda preparam os alunos como se estivessem em séculos passados. Os problemas enfrentados são muitos: falta de infraestrutura adequada, formação e motivação dos professores, não inclusão de tecnologia no Projeto Pedagógico Escolar. Outro problema é que não há uma discussão franca sobre os valores a serem transmitidos e como se deve transmiti-los. Às vezes, em sala de aula nos deparamos com um professor autoritário e pouco afetivo e, certamente, é isto que ele passa ao ensinar como se usa a tecnologia.

É necessário investigar a utilização desse cenário no cotidiano escolar e se o uso da educomunicação com as novas tecnologias e mídias digitais favorecem para aumentar o interesse dos alunos e sua participação integral nas diversas disciplinas do currículo escolar.

A comunicação é básica para o ser humano e para o crescimento intelectual. Através da comunicação, nos relacionamos com o mundo e com as pessoas. No século $X X I$, nossos alunos estão utilizando cada vez mais recursos de informática, tecnologia e comunicação no seu cotidiano. São muitas ferramentas, aplicativos que já fazem parte da vida moderna, já incorporados nos aparelhos celulares e nos novos aparatos tecnológicos. A comunicação instantânea, tanto por escrita ou por vídeos, mudou nossa maneira interagir com as pessoas.

Segundo Schaun (2002, p. 30),

A comunicação está em tudo. Tudo é comunicação, transitando num pântano invisível, transparente, entre linguagens, palavras, discursos, sons, falas, imagens, narrativas, abrigando, ainda, a discussão de uma nova dimensão da realidade, propiciada pela velocidade da luz.

O processo pedagógico exige uma comunicação entre o docente e o discente, mas o professor atualmente deve apresentar um perfil diferente de mestres de séculos passados em que era o detentor do conhecimento; agora o aluno também exerce seu lugar de protagonista na relação ensino e aprendizagem. Na aprendizagem, o aluno já é um protagonista, raramente aceita uma aula expositiva de maneira passiva, e o 
professor dos dias atuais, em geral, procura exercer uma nova postura de atividades críticas e de estimular uma curiosidade epistêmica (GAIA, 2001, p. 39).

A educomunicação associada às atividades pedagógicas da escola amplia a possibilidade de comunicação, promoção e disseminação do conhecimento de maneira democrática, permitindo ao professor e aluno uma integração e um diálogo mediado por tecnologias que estão disponíveis em diversas plataformas digitais, sistemas de comunicação e redes sociais. Fuser (2008), citando texto do professor Ismar de Oliveira Soares:

[...] os objetivos principais da educomunicação são promover o acesso democrático dos cidadãos à produção e difusão da informação; identificar como o mundo é editado nos meios; facilitar o processo ensino-aprendizagem através do uso criativo dos meios de comunicação; promover a expressão comunicativa dos membros da comunidade educativa. [...] (SOARES apud FUSER, 2008, p. 214).

A educomunicação e as mídias digitais podem ser utilizadas como ferramentas de apoio no processo de ensino e aprendizagem colaborativa, permitindo uma interação entre docente e discente, além de permitir que o discente possa se constituir como um ser reflexivo e refletor de novos conhecimentos. A educomunicação pode ser utilizada como ferramenta para criar novos tipos de aprendizagens, tanto formais como informais. (HOPPE; LIBRELOTTO, 2018, p. 1).

Nem sempre é fácil aliar as tecnologias de informação e comunicação a programas e valores éticos do bem comum, mas o professor não desiste e encara este desafio de demandar o aprendizado dos alunos, apesar das lacunas de infraestrutura e de conexão.

Os indicadores de percepção coletados com professores, diretores e coordenadores pedagógicos ajudam a compreender alguns dos aspectos que podem influenciar o uso das tecnologias realizado no espaço escolar. Segundo os educadores, permanecem ainda os desafios relacionados à falta de programas de formação de professores e à infraestrutura, como o número de computadores conectados à Internet disponíveis para uso dos alunos, ou ainda, a qualidade da conexão. (TIC ESCOLAS, 2017, p. 29).

Diversas mídias digitais e sistemas de comunicação podem ser incorporadas no cotidiano escolar e, como o avanço é constante, novas tecnologias surgem e atraem o interesse do aluno e, consequentemente, o interesse pedagógico; afinal, o próprio computador não foi criado para uso nas escolas, nem o DVD, televisão, celular e outros aparatos, mas já são utilizados em diversos projetos em muitas unidades escolares. Os meios de comunicação online e as mídias digitais, quando utilizadas em um contexto pedagógico, despertam o interesse de uso dos alunos, permitindo que o aprendizado mediado por tecnologia torne-se recursos importantes na vida escolar (MARQUES et al., 1995, p. 16).

Por esse caráter atrativo das novas tecnologias de informação e de comunicação é que elas podem - sob a orientação de um professor atento - criar novos comportamentos e atitudes formadores do espírito humano.

\subsubsection{A produção do conhecimento e as novas tecnologias digitais}

A estrutura social de uma sociedade e a forma como o aprendizado é estruturado - a maneira como passa da mãe para filha, de pai para filho, do irmão da mãe para o filho da irmã, do xamã para o noviço, 
dos especialistas mitológicos para o aspirante a especialista determinam muito mais do que o conteúdo real do aprendizado, não só a forma como os indivíduos aprenderão a pensar, mas como o acúmulo de aprendizado, a soma total das peças separadas de habilidades e conhecimento é compartilhado e utilizado. (MEAD apud BAUMAN, 2009, p. 158)

Uma das ferramentas incorporadas no compartilhamento, na disseminação de conhecimento e na comunicação entre docente, discente e comunidades é a rede social (PATRÍCIO; GONÇALVES, 2010, p. 594), que foi absorvida por grande parte da nossa sociedade e que permite a criação, compartilhamento, utilização e divulgação do saber online no texto e na transmissão online.

Existem várias redes sociais que contribuem para uma integração entre as pessoas, proporcionando um relacionamento virtual entre diversos atores no cotidiano da sociedade. Considerar as diversas culturas, os valores, a forma de pensar e crenças de cada uma, permite ver que as mídias de comunicação possuem um potencial expressivo para o uso não somente na comunicação, mas também na educação, o que possibilita expandir as possibilidades pedagógicas e a aquisição de conhecimento.

Toda esta estrutura tende a determinar como somos, sentimos, agimos e existimos. Por este motivo, o professor tem que entrar em campo consciente de sua responsabilidade de formador, pois ele é uma das peças fundamentais de toda esta dinâmica. Ele precisa estimular em sala de aula a interculturalidade entre os alunos, para que haja uma aprendizagem integral.

Quando observamos nosso espaço acadêmico nos vemos cercados por redes sociais diversas que apresentam diversas mídias e diversos formatos que estimulam várias áreas sensoriais e comunicativas conectando e interconectando informações, aprendizados e diversos saberes em seu currículo formal e informal, sobre sua vida, comunidade e cotidiano, esse conjunto de tecnologias favorece o aprendizado de conteúdos do currículo formal e informal, afinal consideramos currículo documento com ação integradora de vários campos educacionais com informações pertinentes (MARTELETO, 2018, p. 2).

Qual será o sentido de se ensinar a técnica e a tecnologia desligadas dos aspectos humanos de produzir um novo conhecimento, que sejam salvaguardas de valores e crenças voltados para a ética e para o humanismo? A sala de aula é um microcosmo e lá existem formas diferentes de fazer, ser e de pensar, que podem ser reunidas em prol de uma formação mais integral do aluno. O que liga estes alunos, se uma proposta intercultural não existe?

As novas tecnologias digitais podem ajudar a romper as barreiras do dogmatismo e do preconceito, mas é preciso um professor atento e sensível, para ministrar o programa de sua Disciplina, a partir de valores mais nobres de convivência, pois nosso destino como humanidade é comum.

\section{METODOLOGIA}

A metodologia usada é qualitativa de caráter teórico e compreende uma pesquisa bibliográfica visando a seleção de autores de referência que acrescentem conceitos e crenças a uma epistemologia da educomunicação. Assim, a metodologia constitui-se num estudo crítico dos princípios e resultados da educomunicação, uma reflexão 
epistemológica para situar os problemas sobre o uso da tecnologia como finalidade e não como meio, que é o lugar privilegiado das tecnologias de informação e comunicação.

\section{CONSIDERAÇÕES FINAIS}

Com base nas literaturas que sustentaram a escrita deste texto, a educomunicação no cotidiano escolar favorece o aprendizado participativo do aluno, democratiza a informação e possibilita uma relação de troca de saber entre o educador e o educando. $\mathrm{O}$ uso das tecnologias com base na comunicação e nas diferentes mídias digitais, com base no currículo formal e informal quando respeita a cultura do educando, permite uma relação ativa na construção do conhecimento e uma autonomia do aluno em seu aprendizado, utilizando ou sendo mediado pela educomunicação apoiada na tecnologia e nas mídias digitais.

Devemos considerar que as redes sociais e mídias digitais são ótimas ferramentas pedagógicas quando pensadas de forma a ajudar na construção colaborativa do conhecimento, compartilhando ações, integrando atividades, facilitando a comunicação e a divulgação do saber. Para que os planos pedagógicos funcionem, é importante perceber que é necessário que haja uma boa integração entre professores, alunos, projetos pedagógicos, que haja também a preocupação com valores e com o uso correto da tecnologia.

Em $40 \%$ das escolas públicas a velocidade de conexão à Internet foi
inferior a 3 Mbps.Sob tais condições, muitas vezes torna-se difícil às
instituições promover o compartilhamento do acesso também entre
alunos e professores. Em 2017 , enquanto $95 \%$ das escolas públicas
possuíam conexão à Internet na sala da coordenação ou direção,
apenas $50 \%$ disponibilizavam acesso na sala de aula. [...] Os dados
mostram que $40 \%$ dos professores afirmaram já ter auxiliado alunos
a enfrentar situações incômodas ocorridas na Internet, tais como
bullying, discriminação, assédio e disseminação de imagens sem
consentimento (TIC ESCOLAS, 2017, p. 29).

A Educomunicação e a utilização de mídias digitais e redes sociais no cotidiano escolar no currículo formal e informal favorecem o aprendizado do aluno, porém devemos ter a certeza de que somente a tecnologia não é suficiente para ter uma tecnologia da educação efetiva, uma educomunicação eficiente na disseminação do saber e do conhecimento do currículo formal e informal; tudo deve ser planejado pedagogicamente para que esse aprendizado seja desafiador, crítico e motivacional, sendo esse aprendizado mediado pelo professor ou pela tecnologia envolvida.

\section{REFERÊNCIAS}

BATISTA, Gustavo Silvano; GOUVEIA, Roberta Alves; SOUZA, Renata de Oliveira. A epistemologia da prática profissional docente: observações acerca de alguns desafios atuais. Ensino Em Re-Vista, Uberlândia, MG, v.23, n.1, p.49-69, jan./jun. 2016, ISSN 1983-1730.

BRITO, Glaucia da Silva; PURIFICAÇÃO, Ivonelia da. Educação e novas tecnologias. um repensar. 2. ed. Curitiba, PR: Editora IBPEX, 2008.

CYSNEIROS, Paulo Gileno - Revista Brasileira de Informática na Educação. n. 5, 
1999. .Disponivel em: http://www.br-ie.org/pub/index.php/rbie/article/ download/2284/2046. Acesso em: 20 abr. 2019.

FEDOCE, Rosângela Spagnol. Mobile technology and the potential of communication in education. 2011. 274 f. Dissertação (Mestrado em Processo Comunicacionais) - Universidade Metodista de São Paulo, São Bernardo do Campo, 2011. Disponível em: http://tede.metodista.br/jspui/bitstream/tede/927/1/Rosangela\%20 Fedoce.pdf. Acesso em: 20 abr. 2019.

FREIRE, Paulo. Pedagogia. Pedagogia da autonomia: Saberes necessários à prática educativa. São Paulo: Paz e Terra, 24 mar. 2014. 144 p.

FUSER, Bruno. Comunicação para a cidadania: caminhos e impasses. Rio de Janeiro: E-papers, 2008.

GAIA, Rossana Viana. Educomunicação \& mídias. Maceió: EdUFAL, 2001.

HOPPE, B C A; LIBRELOTTO, Giovani Rubert. Práticas Educomunicativas no contexto escolar: obstáculos e perspectivas. Disponível em: https://repositorio.ufsm. br/bitstream/handle/1/11807/Hoppe_Barbara_Chiodini_Axt. pdf? sequence=1\&isAllowed=y. Acesso em: 23 set. $\overline{2018}$.

KLERING, Luís Roque. Ambiente virtual de aprendizagem navi: breve história, conceitos norteadores, implicações, potencialidades e aprimoramentos futuros. SINERGIA. Revista do instituto de ciências econômicas, administrativas e contábeis (ICEAC). 2015. Disponívelem: https://periodicos.furg.br/sinergia/article/view/4904/3295. Acesso em: 20 set. 2018.

MARQUES, C.P.C.; MATTOS, M. I.L. de; TAILLE, Y. de la. Computador e ensino: uma aplicação à língua. São Paulo: Ática, 1995.

MARTELETO, Regina Maria. Redes sociais, mediação e apropriação de informações: situando campos, objetos e conceitos na pesquisa em Ciência da Informação. Revista Telfract. n.1, v. 1, n. 1, 2018. Disponível em: https://telematicafractal.com.br/revista/ index.php/telfract/article/view/5/10. Acesso em: 23 set. 2018.

MATTAR, F. Pesquisa de marketing. São Paulo: Ed. Atlas, 1996.

MUNGIOLI, M C P; VIANA, Claudemir Edson; RAMOS, Daniela Osvald. Uma formação inovadora na interface educação e comunicação: aspectos da licenciatura em educomunicação da escola de comunicações e artes da usp. Revista Americana de Ciências de La Educación. 2017.Disponível em: https://www.alaic.org/revista/index. php/alaic/article/view/1030/495. Acesso em: 23 set. 2018.

NCEUSP. Núcleo de Comunicação da Universidade de São Paulo. Apresentação : a educomunicação propõe a construção de ecossistemas comunicativos abertos, dialógicos e criativos. Disponível em: http://www.usp.br/nce/aeducomunicacao/. Acesso em: 20 abr. 2019.

PATRÍCIO, Maria Raquel; GONÇALVES, Vítor. In: ENCONTRO INTERNACIONAL TIC E EDUCAÇÃO, 1., 2010, Lisboa. Anais... Lisboa: Universidade de Lisboa, Instituto de Educação, 2010. p. 593-598. ISBN 978-989-96999-1-5.

PAPERT, Seymour. A Máquina das crianças: repensando a escola na era da informática. Porto Alegre: Artes Médicas, 1994. 
PORTO, Cristiane; SANTOS, Edméa Oliveira dos. Facebook e educação: publicar, curtir, compartilhar. Paraíba: EDUEPB, 2014.

SARTORI, Ademilde Silveira. Educomunicação e sua relação com a escola: a promoção de ecossistemas comunicativos e a aprendizagem distraída. Comunicação, mídia e consumo. São Paulo, v.7, n . 19, p. 33-48 jul. 2010. Disponível em http:// revistacmc.espm.br/index.php/revistacmc/article/view/193/191. Acesso em: 20 abr. 2019.

SCHAUN, Angela. Educomunicação: reflexões e princípios. Rio de Janeiro: Mauad, 2002.

TIC EDUCAÇÃO. ICT IN EDUCATION Survey on the Use of Information and Communication Technologies in Brazilian Schools. Pesquisa Sobre o Uso das Tecnologias de Informação e Comunicação nas Escolas Brasileiras. Núcleo de Informação e Coordenação do Ponto BR Brazilian Network Information Center. 2017. Diesponível em: www.cgi.br Acesso em: 20 abr. 2019.

TIC DOMICÍLIOS. ICT HOUSEHOLDS Survey on the Use of Information and Communication Technologies in Brazilian Households, Pesquisa Sobre o Uso das Tecnologias de Informação e Comunicação nos Domicílios Brasileiros. Comitê Gestor da Internet no Brasil Brazilian Internet Steering Committee. São Paulo 2018. Disponível em: www.cgi.br Acesso em: 20 abr. 2019.

TORRES, Patrícia Lupion; ALCANTARA, Paulo R.; IRALA, Esrom Adriano Freitas. Grupos de consenso: uma proposta de aprendizagem colaborativa para o processo de ensino-aprendizagem. Revista Diálogo Educacional, Curitiba, v. 4, n.13, p.129-145, set./dez. 2004.Disponível em: https://periodicos.pucpr.br/index.php/dialogoeducacional/ article/view/7052/6932. Acesso em: 20 abr. 2019. 